2014

\title{
The Rights We Share: From Rights to Reasons, and Back Again
}

John J. Wilson

Follow this and additional works at: http://digitalcommons.osgoode.yorku.ca/olsrps

\section{Recommended Citation}

Wilson, John J., "The Rights We Share: From Rights to Reasons, and Back Again" (2014). Osgoode Legal Studies Research Paper Series. 9. http://digitalcommons.osgoode.yorku.ca/olsrps/9 


\section{OSGOODE HALL LAW SCHOOL LEGAL STUDIES RESEARCH PAPER SERIES}

Research Paper No. 80

Vol. 10/ Issue. 18/ (2014)

\section{The Rights We Share: From Rights to Reasons, and Back Again}

John J. Wilson

Editors:

Editor-in-Chief: Carys J. Craig (Associate Dean of Research \& Institutional Relations and Associate Professor, Osgoode Hall Law School, York University, Toronto)

Production Editor: James Singh (Osgoode Hall Law School, York University, Toronto)

This paper can be downloaded free of charge from:

http://ssrn.com/abstract=2505639

Further information and a collection of publications from the Osgoode Hall Law School Legal Studies Research Paper Series can be found at:

http://papers.ssrn.com/sol/3/JELJOUR_Results.cfm?form_name=journalbrowse\&journal_id=722488 


\title{
Osgoode Legal Studies Research Paper No. 80
}

Vol. 10/ Issue. 18/ (2014)

\section{The Rights We Share: From Rights to Reasons, and Back Again}

\author{
John J. Wilson
}

\begin{abstract}
:
In this paper, I argue that the contemporary human rights literature would benefit from a shift in focus. Recent accounts of the source and status of human rights have been preoccupied with locating -- or failing to locate -- those fundamental features of persons which would provide a universal grounding for what we call 'human rights.' These accounts have found limited success. Here, I suggest that we ought to move our attention away from the features of rational agents, acting individually or collectively, to the tools with which they are actually acting. That is, we need to fully understand the nature of reasons before we can properly grasp the rights owed to all reasoners.

The paper appeals to recent work in value theory about the connection between reasons and value to moderate a debate between Brian Slattery and Alan Gewirth. Ultimately, it argues that a particular understanding of agent-neutral reasons -- reasons as intersubjectively created and shared between agents of equal value -- must undergird any plausible human rights account. The paper concludes by suggesting that it is our capacity as reasoners and, therefore, as the source of value, which provides the best foundation for an account of human rights.
\end{abstract}

\section{Keywords:}

Human Rights, Value Theory

\author{
Author(s): \\ John J. Wilson \\ Osgoode Hall Law School \\ York University, Toronto \\ E: johnwilson@osgoode.yorku.ca
}


JOHN WILSON $^{1}$

OSGOODE HALL LAW SCHOOL

7 APRIL 2014

The Rights We Share: From Rights to Reasons, and Back Again

In this paper, I will moderate and contribute to a debate between two opposing positions in contemporary human rights literature. In Reason and Morality, and later, Human Rights, Alan Gewirth offers a comprehensive and rigorous rationalist account of the source and status of human rights, derived a priori from what he takes to be the essential preconditions of action for any individual human agent. In “Rights, Communities, and Tradition,” Brian Slattery provides several strong objections to Gewirth's story, before sketching out his own account. In contrast to Gewirth's a priori, individual-based picture, Slattery locates the source and status of human rights in observations about the communal practices and traditions from which human rights doctrines have historically developed, in addition to the virtues that have sustained them (Slattery 460).

The goal of this paper is twofold. First, it will attempt to provide a formal schematic of the basic features that any plausible account of human rights must include. This will be accomplished by a careful rehearsal and critique of both Gewirth and Slattery's positions, to the effect of recognizing the benefits conferred and the burdens carried by each account. An understanding of where each position offers insight or lacks explanatory power will lead to a rough-and-ready sketch of the requirements of an ideal human rights account.

The second goal of the paper is constructive in nature. Here, we will move outside the human rights literature, and appeal to an argument from contemporary value theory to further examine both

\footnotetext{
${ }^{1}$ JD Candidate, 2016. I am grateful to Professor Slattery for his helpful guidance and commentary, and to the members of the Legal Theory Seminar from which this paper emerged.
} 
Gewirth and Slattery's accounts. The key move here is to shift the focus of human rights talk from human beings as rational agents -acting individually or collectively - to the tools with which they are actually acting. That is, we need to understand fully the nature of reasons before we can properly grasp the rights owed to all reasoners.

Human rights claims, by their very nature, must be able to hold across persons: regardless of their ultimate theoretical grounding, they must appeal to reasons whose force can actually be appreciated by all agents. To borrow a term of art from value theory, these claims must be agent-neutral. Taking inspiration from Christine Korsgaard's essay “The Reasons We Can Share,” I will explore two possible justifications for how agent neutral values can come to exert this force, objective realism and intersubjectivism. I will then demonstrate why we should endorse the latter view.

Finally, I will turn back to both human rights accounts at issue, and demonstrate how their respective operative understandings of agent-neutral reasons influence their resulting accounts. In particular, I will show that Gewirth's account draws its logical consistency from a fundamental commitment to the objective realist picture, and that it is this commitment which makes him vulnerable to Slattery's objections. Finally, I will show how an intersubjectivist understanding of reasons can better explain and reinforce Slattery's conclusions about human rights. That is, that an intersubjectivist account makes better sense of the concrete, communal, and historically grounded nature of human rights, while also unwinding the paradox of their immanent-transcendence.

The paper is split into three parts. In Part I, our focus is rights: we will rehearse both accounts at issue, and by critiquing them, build a working formal schematic of what any plausible human rights theory must include. In Part II, we turn to reasons, and rehearse and critique arguments for agent-neutral value writ large, as well as the motivations undergirding the two competing conceptions of agentneutrality. Ultimately, the intersubjectivist conception will be privileged over the objective realist 
picture. In Part III, we synthesize our progress, applying the intersubjectivist picture of reasons to both human rights accounts.

\section{Part I: Rights - Establishing the Formal Schematic}

As stated above, the goal in this portion of the paper is to provide an exegesis and critique of both positions, in order to derive the basic formal features that any human rights story must possess.

We will begin with a rehearsal of the salient features of Gewirth's extensive account. His story on human rights comes out of a larger project, Reason and Morality, which defends an understanding of morality writ large grounded in the necessary features of human action.

For our purposes, we will look to his discussion of the nature of human rights laid out in his Human Rights essay collection. Gewirth begins this discussion with the uncontroversial premise that human rights are a subspecies of moral rights; specifically, that they are moral rights that all persons possess in virtue of their humanity (Human Rights 1). By moral rights, he means claims that are justified by moral principles, and by moral principles, he means statements which are set forth as (i) "categorically obligatory requirements for action" that are (ii) addressed to all agents, and which are (iii) concerned with furthering the most important interests of oneself and others (1). He also distinguishes moral rights, which are justified by moral principles, from legal rights, which find their justification in statutes or other positive legal instruments (2). This makes it clear that Gewirth's area of concern is not the positive human rights instantiated in legal codes, but rather their pre-legal, moral correlates. 
After setting out the species of rights that human rights belong to, Gewirth further clarifies their logical structure. He argues that human rights are examples of what he calls "claim rights" which take the following form:

(a) $A$ has a right to $X$ against $B$ in virtue of $Y$

Here, $A$ is the subject or person who holds the right to $X$, the object of the right. He holds this right against $B$, the person(s) holding correlative duties, because of $Y$, the justifying ground of the right. That is, for $A$ to have a claim right means that she has a right to some thing $(X)$ enforceable against others $(B)$ because of a justification $(Y)$ specific to the right.

Having grasped both the species and logical structure of human rights, we can now describe how Gewirth comes to derive their content.

As a preliminary matter, we must first set out two of Gewirth's background commitments. First, that he takes the fundamental context of morality to be that of human action: "all moral judgments, including right-claims, consist directly or indirectly in precepts about how persons ought to act toward one another... It is thus this context which constitutes the general subject matter of all morality" (Human Rights 46). Second, that all human action is purposive, and that persons act for purposes they regard as $\operatorname{good}(4)$.

Following from these two background commitments comes Gewirth's first contention: that purposively acting agents must logically accept the necessary goodness of certain "generic goods." These two goods, freedom and well-being, provide the necessary conditions for any human action, regardless of what any agent takes as her purpose. Thus, because an agent is always acting for a purpose she deems valuable, then a fortiori, she must also regard as good, whatever conditions are required for 
her to act at all in pursuit of those purposes (47). Adopting what Gewirth calls the conative standpoint, from which the agent makes statements about within her own internal perspective, we can rephrase this as premise (1):

(1) My freedom and well-being are necessary goods

Gewirth's next move is to suggest that from this premise, there also follows a claim on other persons. This is because a corollary of (1) is that the agent's recognition that she must have "whatever further conditions are required" to fulfill those needs (50). Those conditions include that others refrain from interfering with her freedom and well-being. Therefore, an assertion of the necessary conditions of agency also entails, from the conative standpoint:

(2) All other persons must at least refrain from interfering with or removing my freedom and wellbeing

We are now in a position to move to a third conatively-phrased premise that the agent herself possesses certain rights, because the she has identified both a rights-object and a claim on others, based on a justificatory ground of necessity for action:

(3) I have rights to freedom and well-being 
At this point, we are able to add content to (a): $A$, our agent, has a right to $X$, freedom and well-being, against $B$, all other persons, because of justificatory ground $Y$, that these goods are the necessary preconditions of any purposive human action. Gewirth calls these resulting claims "generic rights" (51).

However, what remains is a final move to the recognition from within the conative standpoint that all other agents also have these rights. As Gewirth notes, this move will allow them to move being classed as purely prudential generic rights to moral and human rights.

Gewirth argues that such a move can be made. First, an agent must recognize the sufficient condition for holding generic rights. There is only one potential ground: one's own status as a prospective agent who has ends to pursue (51). To accept anything less or different than this as a sufficient ground would be to deny one's own claim to the generic goods, and thus contradict one's statement in (3). So, on pain of contradiction, every agent must recognize

(4) Being a prospective agent who has ends to pursue is a sufficient condition for holding generic rights

Therefore, in accordance with the principle of universalizability, she must also accept on pain of contradiction:

(5) All prospective agents have generic rights

If all prospective agents have these generic rights, the generic rights retain the status of moral rights and of human rights, as all human beings are either "actual, prospective, or potential" purposive agents (52). 
We have now successfully traced Gewirth's derivation of human rights: from within the conative standpoint, an agent can recognize the conditions of action which she must have, entailing the claim that others not interfere with those conditions, and finally, the recognition that all other agents are able to make those same claims on her.

At this point, we can appreciate the strides this argument has taken in the direction of a comprehensive grounding for pre-legal human rights. Employing little more than the law of noncontradiction and a series of careful a priori reflections from one's internal perspective, Gewirth has generated a set of claims for the generic goods that any individual must make on others. If Gewirth's argument holds water, then -- at least abstractly -- these claims can be made by any individual agent, regardless of her historical and cultural location. Furthermore, the claim has been founded on a seemingly universal feature of human beings: that we are autonomous, purposive actors who see our pursuits as worthwhile. At this point, we can provisionally state that this account possesses a necessary feature of any ideal human rights story: universality. It is not specific to a limited historical period nor a limited number of potential rights-holders. Second, it has provided us with a meaningful account of what human rights are rights to. That is, we now have a workable and determinate inventory of the objects of human rights, namely, freedom and well-being. It should be added, that Gewirth also includes an taxonomy of the latter generic good, which may quell some worries about the viability of the term "wellbeing" (57-59). Thus, we can also provisionally state that the account possesses a second necessary feature of any human rights story: an answer to the question: what rights are human rights?

We can now move to Slattery's concerns with Gewirth's account. Following this, we will turn to the former's alternative account, and offer a similar rehearsal and analysis. 
Slattery provides two related objections to the Gewirth's story. Ultimately, both point to the fact that the generic rights account requires additional premises which the bald picture cannot provide. I will deal with each in turn.

We will refer to the first objection as the "empty agent" objection. It runs as follows: we can accept that $A$ possesses a logically necessary claim on $B$ for the generic rights of freedom well-being, because $A$ must have these goods. The argument that has gone before has made it the case that $A$ must, from logical necessity, make that claim. However, within the confines of the argument, there is nothing about $A$ 's need which makes it the case that $B$ must respect the claim. To use Slattery's phrase, the “character of $A$ 's need" gives $A$ herself a good reason to wish that others will respect her generic rights, but it does not necessarily provide others with a good reason to respect them (456).

What is required then, is an additional premise which would require $B$ to actually respect $A$ 's internally logically necessary claim on him. $B$ must be concerned for $A$ 's welfare: they must be in a state of community; they must be obliged to respect one another's necessary goods. The problem is that Gewirth's conception of agents $A$ and $B$ is empty: "there is nothing in our understanding of ourselves as potential actors that seems to require or justify this assertion" (Slattery 457). Without a fuller picture of agents, one that justifies seeing one another as part of a community, and not isolated actors, there is no way that the logically necessary rights that Gewirth has derived will actually be respected. They will, in effect be Potemkin rights: an elaborately constructed façade which, when push comes to normative shove, fall flat.

We will now turn to Slattery's second objection, which we will call the "limited inference objection." This objection operates in the same way as the empty agent objection, but on a different point in Gewirth's argument. It is triggered by Slattery's observation that when an agent universalizes from (4) to (5) within the conative standpoint, that agent is only committed to recognizing that others 
can make identical conative claims to her own (457). Importantly, this does not give her a reason to recognize an obligation to act on those claims. What is required here, just as in the first objection, is some recognition of community that justifies a concern that those logically identical claims be respected by those who can recognize them.

Taken together, these two objections point to a fundamental concern with Gewirth's story: that a bald individualist account cannot compel agents to be moved by the rights-claims of others. Without a recognition of community, of mutual respect and concern, we cannot provide a justification for why $B$ should respect the claim that $A$ must logically make against him. Troublingly, Gewirth's generic claimrights, cleanly defined, rigorously derived, and universally held in the universe of the a priori, provide no necessary ground for respect in the realm of flesh and blood. This is perhaps especially damaging to an account of human rights, which deals exclusively with a class of claims that aim to exert normative force across all persons. This lacuna in Gewirth's story leads us to a third necessary feature of any human rights account: the resulting picture of rights should compel, or at least be capable of compelling universal respect. In short, it must provide for reciprocity. Logically necessary, conative statements may provide universal rights-claims, but these claims must also allow recognition from without. Without a tenable explanation of the universal normative force of the rights derived, any story of human rights will fall short.

Having gleaned what we can from Slattery's objections to Gewirth's specific account, we should pause to see how they speak to Slattery's overall concern with the general class of projects of which Gewirth is representative. This will lead us smoothly into Slattery's own account.

"Rights, Communities, and Tradition" begins with a story from Robert Coles concerning the interactions of a white teenager (Slattery calls him "Jim") and a black classmate ("Martin") in a recently integrated school in the American South (447). Coles' story traces Jim's changing moral attitudes 
towards Martin. Initially, Jim denied any communal bonds with Martin, and joined his friends in insulting and assaulting the black students. However, a moment of "spontaneous empathy" in which Jim apologizes to Martin leads him to start to see Martin as a human being: "I began to see a kid... a guy who knew how to smile when it was rough going, and who walked straight and tall, and was polite" (Slattery, quoting Coles, 449). Martin's courage and "grace in adversity" leads Jim to recognize in Martin virtues that his own community endorsed, leading to a recognition of communal bonds that would eventually extend to include both Martin and his other black classmates (449). By coming to recognize that Martin possessed many of the features that defined personhood within Jim's community, Jim then "simply extended the existing standards of his community to someone previously viewed as an outsider," transcending the racist attitudes of his friends and bringing Martin into the realm of equal concern. As noted by Slattery, this norm of equal concern was already immanent in Jim's community it was a "just way of treating other members" (451).

Slattery sees this brief story as suggestive of important considerations about the character and origins of human rights doctrines. First, that human rights doctrines, although cast in abstract terms, arise out of "concrete moral insights into relations with others, just like Jim's interactions with Martin (451). Furthermore, recognition of another's human rights follows an acceptance of that other agent's membership in a community: rights do not precede communal ties, they presuppose them (451). Third, they are born out of particular historical circumstances in which those relations and communal ties exist: Jim and Martin's interactions did not occur in a vacuum. Finally, they promise some kind of moral transcendence or affinity with a higher truth that is paradoxically already recognized and immanently instantiated in the respect between community members. Taken together, Slattery notes the lessons from Coles' story interpret human rights as "concrete," "communal," "historically grounded," and "immanently transcendent" (452). 
This depiction of human rights stands in stark contrast to the abstract, individual, ahistorical, and rationally-based conception offered by accounts like Gewirth's. Slattery levels two charges against these kinds of accounts: first, that they do not capture the actual genealogy of human rights doctrines (452). An ahistorical account cannot explain "the historical realities of human rights movements" such as those aimed at achieving religious tolerance, abolishing slavery, and the like (452). Furthermore, such accounts actually get the genealogy of rights recognition backwards: individuals do not come to communities holding rights which then structure the community; rather, the immanent truths and virtues of the community, when recognized in agents, vest those agents with rights. Rights presuppose communal ties (452).

We are now in a position to move into Slattery's position in earnest. He begins by noting the sceptical insight of Alasdair MacIntyre that we should not believe in human rights in the absence of good reasons for that belief (459). And, as evidenced by the objections laid out above, he does not think that the individual rationalist accounts provide such reasons. However, he does not follow MacIntyre through to the sceptical conclusion that human rights are mere fictions. For Slattery, the suspect reasons offered by the rationalist camp do not exhaust the kinds of 'good reasons' we might have for accepting human rights. Rather, he suggests that our belief in human rights can be grounded in something outside rational necessity:

I think that our acceptance of universal human rights can be justified in another way, one that appeals to the communal practices and traditions within which doctrines of human rights have evolved historically, and to the virtues of tolerance and respect that sustain them (Slattery 460) 
Slattery begins his account with a discussion of the nature of moral reasoning, which, as noted by Gewirth, will include among its subject matter reasoning about human rights. The upshot of this discussion is a finding that systems of moral reasoning are not unlike those of the common law: they include a set of largely accepted governing principles which are then applied to particular subject matters, such as the permissibility of abortion, through the drawing of analogies and distinctions (462463). Importantly, these governing principles form part of a unique "living moral tradition" of spheres of practices and the goods and standards those spheres support.

A fortiori, as a subspecies of moral claims, human rights will also arise and find their resolution within particular moral traditions. This further supports Slattery's earlier objections to Gewirth's picture: we will not reach conclusions about what is owed to persons through a priori reasoning.

However, as noted by both Slattery and MacIntyre, this leads us to a potential worry: how can human rights be at once universal in their aspirations and yet necessarily grounded in particular moral systems or living moral traditions? Slattery quells the worry by setting out four distinguishable propositions about the (i) origins, (ii) scope, (iii) mode of justification, and (iv) persuasive force of moral reasoning, and showing that affirming the first does not entail necessary limitations on the following three. We begin with:

(i) Moral reasoning, including reasoning about human rights, necessarily draws on a particular ongoing moral tradition and body of social practice

The foregoing discussion about the common law-like nature of moral reasoning suggests that this proposition is true. However, Slattery is careful to point out that it does not entail the conclusion that 
(ii) Moral reasoning is necessarily limited by the bounds of the community from which it originates

That is, the community-based genesis of a moral tradition does not limit the potential applicability of the tenets it produces to that of the community. Slattery offers a useful analogy: modern scientists work within a tradition of inquiry separate from or incompatible with other traditions, such as astrology, but this in itself is not a sufficient ground to doubt the universal applicability of their theories (465).

Similarly, an acceptance of (i) does not entail that

(iii) Moral reasoning is necessarily justified by reference to socially attributed roles or realities

Slattery notes that although socially-specific norms do influence "everyday morality," there is an important sense in which morality is concerned with structuring the relationship between the actual and the ideal. That is, a focus on actual societal practices allows one to theorize about the practices of the ideal society, or as Slattery puts it: "our knowledge of the ideal is gained through familiarity with the actual" (466). Moral reasoning does not seek to replace the knowledge derived from communal practices, but to add to it, to transform it. Thus, justifications for moral norms do not just lie in the folkways - we see the defects in the actual and envisage the ideal in relief.

Finally, a commitment to (i) does not entail that

(iv) Moral reasoning's persuasive force is internally limited to those inhabiting any one tradition 
Any survey of the history of community-transcending ideas, such as those of great prophets and reformers, falsies this premise. It is simply not the case that an ideas origins limit its force.

Having established that MacIntyre's worry of inherent limitations is not tenable, Slattery provides a brief, community-based sketch of what he takes to be the source and status of human rights. He writes, "Human rights represent, I think, the gradual unfolding of the meaning and requirements of commitments to certain basic values or goods, which are experienced as lying beyond the practices where they are first encountered" (466). He notes that there are many basic values or goods, but takes that of friendship as salient, because of the role it plays in bringing home to us the intrinsic worth of others (467).

It seems then, that Slattery's position is that these goods, such as friendship, unfold differently and incrementally in each social context, and that each community, over time, discovers how to instantiate those goods within the context of their ongoing moral traditions. It is a process of coming to understand, of coming to appreciate others: we move from the concern for welfare of friends to the importance of persons in general with the help of "simple forms of respect such as politeness" (467).

We are now in a position to appreciate the contribution that Slattery's picture provides. This account, and the arguments motivating it, give us two additional features for our formal schematic. First, a tenable account must possess a general sensitivity to the historical realities and genesis of human rights practice. Second, and as a specific corollary of the first, it must also posit a particular relationship between communal bonds and rights-claims. Historical awareness requires the view that rights presuppose and require communal bonds, not the other way around. If we do not adopt this specific genealogy, we are left with individual possessing some sort of pre-communal claim rights, which, as we have seen from our discussion of Gewirth, does not compel respect from others. In short, the recognition that communal bounds precede rights ensures reciprocity - a requirement we have already recognized. 
In addition to providing us with these two requirements, the account also successfully argues against the contagious scepticism of relativist claims by showing that the genesis of a moral principle or practice does not limit its scope, source of justification, or persuasive force.

At this point, we have accomplished our first goal, and can propose the formal features required for any tenable account of human rights. Our initial rehearsal of Gewirth's view identified two important features: universality of scope and determinateness of content about rights-objects. That is, we recognized that an account must be able to include the entire set of human persons, regardless of their social or historical location, and that it allow us to clearly state what those human persons are entitled to by providing a workable set of rights objects.

Slattery's objections to Gewirth's picture provided us with the third requirement of reciprocity. That is, the resulting picture of rights claims should compel, or at least be capable of compelling universal respect. Finally, our rehearsal of Slattery's own position has given us two other features. First, that the account can capture how the practice and doctrine of human rights have evolved historically. We shall call this feature historical veracity. And finally, following from the requirement of reciprocity, that the account posits that communal bonds precede and are presupposed by rights claims.

We can now say that an account of human rights must (i) be universal in scope, (ii) be sufficiently determinate in right-objects, (iii) be capable of supporting reciprocity, (iv) possess historical veracity, and (v) posit the right relationship between communal bonds and rights claims.

Furthermore, upon consideration, these five features interact with one another, creating an interdependent whole. We can note the following relationships between these formal features: in addition to serving as the necessary basis of any human rights claim, universality operates as an upper bound on the second requirement of determinateness of rights-objects. Though it is important that an account provide a clear indication of what rights-objects are protected, those objects themselves must 
not be so specific as to compromise the universality of the picture. That is, they must be sufficiently general as to be applicable to all human persons, and not to any limited set of persons. Universality also imprints itself into the requirement of reciprocity: as we have seen, the account must provide for the possibility of any agent respecting the rights-claims of another as having normative force for him. Our concern with historical veracity serves as the lower bound for determinateness of rights objects: if the rights objects identified are too general, they may compromise the ability of the account to make sense of how human rights doctrines have developed over time. Finally, we can understand the requirement of positing the existence of communal bonds before rights as being grounded and informed by the requirement of historical veracity and by the requirement of reciprocity.

\section{Part II: From Rights to Reasons}

We will now shift our focus from rights to reasons. From what has gone before, we know that human rights most possess, among others, the necessary formal features of universality and reciprocity. For these reasons, human rights claims must, by their nature, be grounded in reasons that exert normative force over all agents. To use a term of art, they require the existence and support of agentneutral reasons. This portion of the paper will explain the source and status of this category of reasons. After distinguishing agent-neutral from agent-relative reasons, we will rehearse a further distinction between two explanations of agent-neutral value, and endorse one over the other. The section will borrow from Christine Korsgaard's essay “The Reasons We Can Share," in which she explores the distinction between agent-neutral and agent-relative value.

Korsgaard begins her discussion by assuming an equivalence, "or at least a direct correspondence" between reasons and values. In particular, the reasons at issue are practical reasons, 
that is, reasons that bottom out in action. Put simply, to say that there is a practical reason for something is to say that the thing is good or valuable, and vice versa (25). The following discussion will move forward with that assumption in place.

Her first move is to explain the agent-relative/agent-neutral distinction with regards to reasons. In more traditional parlance, this distinction marks the difference between subjectivity and objectivity. When applied to reasons, the subjective-objective divide tracks the scope of a reason's normative force. That is, to say that something is an agent-relative reason is to say that that reason holds for that agent. Similarly, to say that something is an agent-neutral reason is to say that the reason holds for all agents. Korsgaard borrows Thomas Nagel's understanding of the difference from The Possibility of Altruism: "According to Nagel, a subjective or agent-relative reason is a reason only for a particular agent to promote something; an objective reason is a reason for anyone to promote the thing" (25-26). We can also parse the distinction into value talk, or in terms of goodness: subjective reasons evoke the concept of "good-for" while objective reasons evoke the concept of "good-absolutely" (26).

Her second move is to add a further distinction within the latter category. Korsgaard argues that a claim for the neutrality of a reason, the claim that something is a reason for everyone, may be understood in two different ways (27).

On the first view, which Korsgaard calls objective realism, agent-neutrality can be explained metaphysically. Values hold for all agents because their existence is prior to and independent of any agents taking an interest in promoting them. These values are not created or generated, but are part of the fabric of the universe. Korsgaard likens the objective realist picture of agent-neutral reasons to the idea of light from the sun: values provide reasons for us in the same way that the sun provides light for us: "because it's out there, shining down" (28). Continuing the analogy, on this picture, just as the sun's 
existence is not contingent on light-sensing organisms, values exist without those who can see and respond to reasons.

This metaphysical explanation comes with three corollaries. First, one has to commit to a particular ordering of priority between agent-neutral and agent-relative values. The latter are derived from the former. Agents first come to recognize something's objective value and then come to internalize it for themselves, generating agent-relative reasons. Second, and following from the first, agents generating values are involved in an epistemological exercise of discovery. Somehow, before generating "value-for-them," they must first come to perceive these objective values. The objective realist must provide an account of how this is possible. Finally, and perhaps most interestingly, an objective realist account allows for the possibility of adding and weighing values: if something's goodness, for example, the goodness of happiness, exists in the object itself, then it is possible to say that the happiness of two persons will be better than that of one. Thus, an objective realist can be a consequentialist (28-29).

The second view, which Korsgaard calls intersubjectivism, does not explain agent neutrality as a function of metaphysical independence. In fact, on this picture, all value is contingent on the existence of agents. Every ascription of value requires an agent; everything that is good or bad has that property because it is good or bad for someone. The intersubjectivist eschews the possibility of something's value being distinct from some agent, because it is in its relation to them that it attains its character. Thus, for the intersubjectivist, human persons themselves, not the mind-independent fabric of the universe, are the source of value. ${ }^{2}$ On this view, agent-neutrality refers to identity independence: value requires agents for its existence, but its goodness is not indexed to any one agent. Neutral reasons, on this view, are shared.

\footnotetext{
${ }^{2}$ Professor Slattery has raised, correctly, that the intersubjectivist may not be entitled to a conclusion of this strength. A value's contingency on the existence of an agent does not, without more, entail that that agent is the source of the value. She may, instead, be a necessary precondition or component of the value.
} 
Like the objective realist view, the intersubjectivist account of agent-neutrality entails several commitments. First, the order of priority between agent-neutral and agent-relative reasons is reversed: objective values are constructed from subjective ones (28). Individual agents find something in the world that is good-for-them, generating agent-relative reasons. These reasons then become objective when, "because of the attitude we take towards one another, we come to share each other's ends" (28). It is this process, the recognition that another's ends might be shareable, which then makes that agentrelative reason agent-neutral.

Following from this, agents don't discover agent-neutral values on their own. Rather, they construct them together. Finally, if value is always relative to some agent, although not any specified agent, there is no possibility of adding values across from different persons. As Korsgaard writes, "my happiness is good for me, and yours is good for you, but the sum of these is not good for anyone" (29). So, the intersubjectivist must deny that the sum of these two values is a value at all. And, since consequentialism trades on the assumption that value can be added, an intersubjectivist cannot be a consequentialist.

As stated above, the latter position will be shown to be superior for our purposes. However, before we can endorse intersubjectivism over objective realism, we must show that there exist agentneutral reasons in the first place. Korsgaard begins this process by rehearsing the first of two arguments by Thomas Nagel around which her paper is structured. In The Possibility of Altruism, Nagel offers an argument for rational altruism - later abandoned, for reasons we shall see-which demonstrates that all subjective reasons have objective correlates. That is, in order for me to view something as good-for-me, I must also regard it as good-absolutely. We should note that Nagel does not employ the objective realist/intersubjectivist distinction. 
Nagel makes the argument by appealing to a very common moral device to which many of us are susceptible, encapsulated in the question: "How would you like it if someone did that to you?" (1970 82). Imagine that, out of the blue, a stranger accosts you and begins to hit you with a stick. When you attempt to reason with the stick-wielder, you ask the aforementioned question. This question invites the stick wielder to enter the realm of the impersonal, where we regard each person as equally real, and put herself in your shoes. Nagel says that in such a situation, where she imagines that the roles were reversed, the stick wielder would reach a particular judgment: that she would herself resent being randomly beaten with the stick. That resentment, what she "feels," Nagel argues, signals a belief that her discomfort gives you, the one now wielding the stick, "a reason to terminate or modify your contribution to it" (83). In other words, if she feels resentment, she must admit that she views her subjective reason for the beating to cease as exerting normative force over you. Once she recognizes this, she is also committed to holding that your reasons have normative force over her. Thus, Nagel argues, where there exists a subjective reason indexed to a person just as real as any other person, that subjective reason provides an objective or agent-neutral reason that the other equally real persons must respond to (1970 83).

As indicated above, Nagel eventually abandons this conclusion. Careful readers may have already bristled at the overall suggestion, perhaps noting that there seems to be something incorrect about the idea that all agent-relative reasons having objective correlates that others must respect. Certainly, one might think, there are reasons that I possess that don't hold any normative force over you. Considerations along these general lines are what Korsgaard believes led to the modification of Nagel's position. In The View From Nowhere, he argues that there are some categories of reasons which, though agent-relative, do not admit of objective correlates. The first category, what Nagel terms "reasons of autonomy" and what Korsgaard renames "ambitions" will be the focus of our discussion. 
For Nagel, reasons of autonomy are reasons that spring from the agent's personal and special relationship with his own projects. That is, my relation to a certain personal goal, to use Nagel's example, my desire to climb Mount Kilimanjaro, seems to give me a strong reason to pursue that goal (1986 167). However, it is not clear, as in the case of the stick-wielder above, that my strong agentrelative reason gives you a reason to care that I reach the summit or to help me do so.

Korsgaard calls these kinds of reasons "ambitions," and notes the pull of Nagel's intuition: "it appears as if an agent has excellent subjective reasons for doing things which from an objective point of view are either completely worthless or obviously inferior to other things which she might do" (33). However, she provides a careful analysis of the structure of ambition which suggests that within each ostensibly subjective value pursued in instances of ambition, there also exists a necessary objective value. Furthermore, she argues, that this objective value must be what grounds the ambition itself.

Korsgaard's illustrative example is that of her desire to write a book about Kantian ethics that will become "required reading" for all ethics classes (37). On Nagel's account, this is an agent-relative value, as it only gives Korsgaard a reason to try to bring it about that her book becomes required reading. To have an ambition is to have a desire for a special object that you view as subjectively good for you alone. The fact that Korsgaard wants her book to be required reading does not give anyone else a reason to require her book. Upon reflection, the agent will realize that the only reason that could provide others with normative force to require her book would be that the book itself was a good book, and thus she might set out to write that good book for instrumental reasons (37).

Korsgaard suggests that this analysis of how ambition works implies a very strange underlying structure: it suggests that her desire to have her book be required reading is the product of a kind of vanity, and writing a good book happens to be one way of satisfying that vanity. Upon recognizing this, 
one takes the "good book" route to one's ends. Formally, Nagel's proposed structure for ambition looks like this:

(i) I want my book to be required reading (this is an agent-relative end)

(ii) Therefore, I shall write a good book (as a means to my agent-relative end)

Korsgaard argues that this structure does not correctly reflect how agents actually form ambitions. In her case, part of the reason that she wants to write a book on Kant's ethics is that such a book would be a good thing in its own right; it is an ambition to do something good, and that portion of the ambition would not be served by people requiring the book regardless of whether it was good or not (37). It seems then, that a necessary part of the structure of ambition is the recognition of a good. We can rephrase this as (iii) Korsgaard thinks that someone should write a book on Kant's ethics good enough that it become required reading. Phrased this way, it has neutral value.

But this impersonal statement swings too far from in the opposite direction: it doesn't tell us why she has a reason to write the book, and why we have ambitions in the first place. It is still the case that Korsgaard may really like the idea of her book being required reading. Korsgaard writes that there must be, in addition to the agent-neutral value of the book in its own right, an inalienably agent-relative component to ambition. She wants to be the someone who writes the book in (iii). So, she proposes the following structure for ambition:

(iii) I think that someone should write a good book on Kant's ethics (an agent-neutral end)

(iv) I want to be that someone (an agent-relative motive) 
So characterized, ambition is not, as Nagel would have it, a desire for some special object that you believe to be good for you subjectively, but rather to "want to stand in a special relationship to something that you think is good objectively" (38).

Nagel may reply, at this point, that the agent-relative motive in (iv) still proves his thesis: that ambitions, or reasons or autonomy, in his own parlance, don't give exert normative force over others. Korsgaard has a very interesting reply. She writes that although the subjective component is necessary, it cannot be what provides the agent with a reason for action. This is because taking our own desires as the true reasons for action leads to repugnant results.

If Korsgaard took seriously the belief that her agent-relative motive was a reason for action, this would license means other than writing a good book to achieve that end, if those means were efficacious. If her desire itself gives her reason to act, it gives her a reason to prevent other Kantian scholars from pursuing their own projects. As Korsgaard notes, this is not an expression of ambition, but a perversion of it (38). To avoid this perversion, we must hold that what gives her a reason to act is the agent-neutral end in (iii).

Korsgaard goes on to write that other ambitions, such as those structured around important relationships also take this form. Consider love. The underlying structure takes the same form: out of a recognition of an objective good - my loved one's happiness - I think that someone should make her happy. Furthermore, I really want to be that someone. But, if I take that latter desire as a reason for action and prevent others from making her happy, or if I think that her happiness has no value unless I am the one producing it, I am no longer expressing love. Rather, what I'm expressing is an awful perversion of it (39).

The upshot of these examples is to show that even deeply personal values, those which are ostensibly and undeniably agent-relative, contain a necessary agent-neutral component in addition to the 
obvious agent-relative component. Furthermore, and more importantly, it must be that the former is truly the agent's reason for action.

At this point, a careful reader might observe that both examples smuggle in an appeal to some overriding 'objective value' that makes it easy to endorse (iii): in the first case, that of a good book on Kant's ethics, in the latter, the happiness of another. Ambitions, one might say, vary widely, and not all ambitions actually aim to produce something good.

For instance, it is difficult to imagine the agent-neutral value of one's ambition to climb mount Kilimanjaro, or, in a more eccentric vein, become the world's foremost collector of potato chips that look like celebrities.

However, we need not assume that there are no good reasons behind a personal project merely because some particular ambition's end seems eccentric, odd, or at first blush, vacuous. As Korsgaard writes, there are reasons for caring about these kinds of things, and those reasons can be articulated (39). If you ask a mountain climber why she chooses to climb, she may offer you some surprisingly attractive reasons. Indeed, she likely takes her desire to be motivated by the particularly good-making features of climbing: the beautiful views, the thrill of physical activity, the satisfaction of conquering goals that one sets for oneself (39). Now, a climber may not actually offer those reasons. It is possible that she might also say "because I want to." However, Korsgaard thinks that when a person offers this reply, she is not offering a reason or an explanation. Rather, she is "setting up a bulwark against incomprehension;" she is deciding, for some other reason, not to share her true reasons for climbing (40). Perhaps she feels inarticulate, or believes that you will not be able to understand. But this does not mean that an eccentric ambition does not appeal to some underlying values that we can recognize the good in. In fact, when that bulwark is not put up, and the articulate speak about the reasons for their interests, something important happens: "you hear the familiar voice of humanity, not the voice of alien idiosyncracies" (40). 
I think there is something important in this last point. When persons "put down their guard," when they attempt to offer their views on what they care about, perhaps by openly sharing what they take to be the truly good-making features of their pursuits, they attempt, and sometimes succeed to form a bond with their listeners. There is a sense in which the person offering their reasons and the person attempting to grasp them come to share something together. In this process of conversation, of attempting to articulate and understand one another, it is almost as though some third thing is generated, or perhaps discovered. The two persons, or so it feels, are participating in or with something larger than themselves. Now, it may be the case that we will never know what this "third thing" is, however, one need only contemplate one's last great or memorable conversation to understand this phenomenological point.

Even without the phenomenological acuity of Korsgaard's last observation, her overall argument for the structure of ambition is one we should endorse. It better captures how we think about our own projects and avoids the Nagel's error of labeling as genuine ambitions cases of "familiar perversions." Without hesitation then, it seems that we can hold that the prima facie agent-relative category of ambition-reasons is wholly undergirded by agent-neutral values. The upshot of all of this is that Nagel's initial position in The Possibility of Altruism was correct: we should recognize that all agent-relative reasons have objective correlates, even the most ostensible subjective or eccentric.

\section{II (a) Objective Realism or Intersubjectivism?}

Consider our eccentric ambition mentioned above: that of wanting to become the world's leading collector of potato chips that happen to look like celebrities. From what has gone before, we are 
committed to holding that the collector's ambitions are grounded in agent-neutral values or reasons. We can now consider which of the two accounts Korsgaard sets out makes better sense of this neutrality.

Recall that the objective realist claim about agent-neutrality is essentially metaphysical: that reasons exist prior to and independent of agents. In this case, an objective realist is committed to holding that the agent-neutral value of celebrity potato chip collecting is somehow out there, independent of any potato chip collecting agents. Furthermore, they must also hold and explain that at some point, our ambitious collector has managed to discover that independently existing goodness, and, that he now derives subjective value from it by taking it as his own.

This view does not seem particularly attractive, for several reasons. First, it quickly becomes clear that we have to posit an entire realm of metaphysically-independent undergirding every conceivable ambition. At the very least, once we recall Korsgaard's suggestion that there are recognizably good-making features beneath our disparate interests, like the thrill of physical activity animating the mountain climber, we must at least posit a similar set of these values that map onto potato chip collecting. Even on the latter, less extensive account, we must still posit the existence of some set of new values within the fabric of reality. Furthermore, the objective realist must also provide us with some epistemic machinery with which to discover and appreciate those values.

In contrast, consider how the intersubjectivist explains the neutral value of our collector's ambition. Recall that for the intersubjectivist, value is always indexed to some agent or another, and that neutral value is constructed from a subjective end being recognized as shareable by other agents. The interest of our ambitious collector creates the initial agent-relative value. The source of the ambition's goodness is not an independent metaphysical reality; it is the collector himself, demonstrating an instance of a unique human capacity to take an interest in something. The ambition is not good because of the independent value of chosen end, it is good because its end was chosen. 
Once that value is generated, he along with others, construct its neutral value. His actions, and, if he is articulate, his words, communicate his own reasons for his interest. Then, when another recognizes that activity as an expression of interest, a remarkable thing happens: as Korsgaard writes, "the Intersubjectivist sees the other as human, and therefore shares or tries to share the other's ends" (40). That is, the fact that an agent is an interest-taker or value-creator provides one with the reason to respect the resulting reasons. The second agent sees those ends that she could endorse as a fellow agent.

This has important consequences for how agent-relative reasons can hold across persons. On an intersubjectivist account, the mere fact that an end is chosen is itself sufficient to create agent-neutrality. This gives the intersubjectivist a reason to recognize the ends of others as shareable and help others pursue their ambitions. On an objective realist account, however, the relation is reversed, as one must recognize the end as valuable before respecting it: the objective realist sees no reason to help unless he first sees the other's ends as ones he can endorse (40).

This consequence, unique to the objective realist, is particularly troubling because it provides a narrow and limited explanation of when one can be compelled to act in the interest of others. Now, on this view, the possibility of taking another's reasons as reasons for action requires that you first share her ends. This is the result of the objective realist's locating of value outside the agent. In contrast, the intersubjectivist's recognition of persons as the source of all potential value means that the ends of others should be promoted, simply out of respect for the persons who have them. The intersubjectivist would say that to value only the end and not the agent is morally repugnant.

At this point, however, one may object that all agents must now respond to all agent-neutral reasons generated through intersubjective sharing. However, we cannot be obliged to respond to all reasons for the simple reason of impossibility. Ought implies can: we cannot be motivated by a moral 
ought without the possibility of fulfilling that obligation. The limits of possibility, and in many cases, proximity, sketch the bounds of our obligations to others on the intersubjectivist picture.

One might be pleased with that reply: certainly, any workable account must not cast our net of obligation too wide. However, a sophisticated objector might wonder if this picture does not do justice to cases that involve close proximity. Specifically, that the intersubjectivist cannot explain the deeper commitments one might feel towards the reasons or values of those in one's community.

Korsgaard has a reply ready for this objection as well. She notes that it not uncommon for persons to share the ambitions of others in a more profound way. From what has gone before, all that is required is that we recognize that the ends of another could be shared, that we are committed to the possibility that another agent could explain to you "what is good about the world as she sees it through the eyes of her ambition" (41). However, you might go further than committing to the possibility of sharing an end. You may actually come to see the value of the other's end, and take it as your own. Remarkably then, you then share the same ambition, and the value functions as if it were a value in the objective realist sense (41). It becomes a fact about your relationship that you both share this end, and as a result, certain special obligations arise. This, Korsgaard thinks, explains the deeper bonds one feels with one's community.

The above discussion has established that the intersubjectivist account of the agent-neutrality of reasons should be endorsed over the objective realist position. The former does not come saddled with the latter's metaphysical or epistemological baggage, and is able to offer an account of value that can accommodate any agent's genuine interests. It also provides other agents with a scope of obligation that is not impossibly wide and sensitive enough to capture the deeper bonds of closer relationships. 


\section{Part III: ... And Back Again}

We have almost reached the conclusion of our journey. Fittingly, we will end as we began, by considering Gewirth and Slattery. My final goal is to apply what we have learned about the structure of reasons to these accounts that sketch what we owe reasoners. Armed with a robust theory of agentneutral value, on which reasons are intersubjectively shared, I think we can make better sense of both accounts, and come to a surprising conclusion about the relationship between rights and reasons.

I would like to frame this last discussion using one final thought from Korsgaard. In the introduction to "The Reasons We Can Share," she writes that twentieth century moral philosophy will be seen by future thinkers as a struggle to escape utilitarianism. Many non-consequentialists are to blame for this, as they have internalized a consequentialist outlook on morality as a whole, and make the mistake of unconsciously assuming that the business of morality is to bring something about (24). Even in objecting to consequentialist directives, they phrase their responses in what the moral agent ought to bring about or how she ought to do it. More importantly, they make the fundamental error of assuming that the "primal scene," or basic stage of morality is one in which someone does something to or for someone else. It is wrong, according to Korsgaard, for one's moral focus to emphasize what happens to one agent or another, rather than on the attitudes of the agents involved. For Korsgaard, and indeed, as we will see, for us, the primal scene of morality is not one in which I do something to you, but in which we do something together. And furthermore, the subject matter of not morality is not what we should bring about in the world, but how we should relate to one another (25).

Neither of the human rights projects we have engaged with can be plausibly characterized as consequentialist. If they were, they would likely be fundamentally inconsistent. The normative force of a human rights claim cannot be contingent on circumstance and luck, on a determination of whether or not 
its enforcement would be optimific. In fact, it is precisely amidst the slings and arrows of the most outrageous of fortunes that we need human rights claims to maintain their force. By their nature, they aspire to be fundamental and immutable. They command unwavering respect in virtue of their status as a protector of the dignity of persons.

Upon reflection, however, it appears that Korsgaard's charge of consequentialist influence does apply to Gewirth's non-consequentialist story. And, it is Gewirth's incorrect understanding of the primal scene and business of morality which ultimately makes him vulnerable to Slattery's objections.

We can see the consequentialist perception of morality's business and primal scene in the foundation undergirding Gewirth's account. First, his definition of moral principles betrays this influence on what he takes to be morality's goal: moral principles are claims that are "concerned with furthering the interests, especially the most important interests of persons or recipients other than or in addition to the agent or the speaker" (Human Rights 1 ). On his own view, the very principles of morality operate in order to facilitate interests, that is, to bring something about. Second, his description of the "fundamental context of morality" serves to demonstrate his understanding of the primal scene of morality. In Human Rights, he writes that the fundamental context of morality is human action, the pursuit of ends, and that moral precepts structure "how persons ought to act toward one another." Here, he does precisely what Korsgaard cautions against. That is, he takes morality's primal scene to be one in which I do something to you, or you to me, not one in which we do something together.

This understanding of morality's business and primal scene is then reflected in his picture of human rights. The generic goods of freedom and well-being, Gewirth's human rights-objects, are those which allow an individual to act, to bring about their ends. Recall that Gewirth begins from the primitive that persons always act for purposes they regard as good; that everyone always sees their ends as worthwhile. This was first captured over two thousand years ago in Plato's Protagoras, in which 
Socrates shows us that "no one goes willingly towards the bad" (358d). Gewirth uses this basic premise to motivate the conative statement that one must also regard as necessarily good those things required for the agent to pursue those ends. Recall his first two premises:

(1) My freedom and well-being are necessary goods

and

(2) All other persons must at least refrain from interfering or removing my freedom and well being

The first premise is indexed to and draws its strength from the goodness of the ends chosen, consistent with the consequentialist perspective on morality in which it is morality's business is to bring something about. The second then posits a particular obligation of non-interference within the moral arena, framing the basis of Gewirth's human rights claims on an understanding of the primal scene of morality as one in which agents do things to one another.

So, Gewirth is suffering from a case of consequentialist influence. The source of this perception, as some readers may have guessed, is his implicit objective realist interpretation of agent-neutral value. As stated above, premises (1) and (2) gain their force from the goodness of the ends chosen by the agent, not from the agent himself. This is the essence of objective realism. It is this focus on the value of the agent's end, independent of the agent, which creates the impossibility of reciprocity that Slattery observes. 
Recall that both of Slattery's objections to Gewirth's account showed us that a bald individualist account cannot compel others to respect an individual's claims on them. In what I called the emptyagent problem, Slattery argued that in order to make reciprocity possible, Gewirth needs an additional premise which explains why $B$ is obliged to respect $A$ 's claim in (2), and that "nothing in our understanding of ourselves as potential actors seems to require or justify this assertion." Similarly, in what I called the "limited inference objection," the same need arises. Slattery parses the problem in terms of a gap between the individual and community: there needs to be something else about agent $A$ that ties him to agent $B$ such that $B$ will respect $A$ 's claim for generic rights. Slattery then suggests that the additional premise that would bridge that gap and provide a ground for obligation is that the two agents participate in a community, that there be some sort of minimal sympathy between them. But, on Gewirth's view, all we have are empty pictures of persons who happen to have ends.

This analysis is persuasive in its own right. However, I think it also tacitly trades on the objective realist conception of agent-neutral reasons assumed by Gewirth. If value and normative force are located outside the agent, in his ends themselves, then his bald claim that I have obligations to respect those reasons can only have force on me if I share those ends. Seen in this light, we can see that Slattery's objections track the potential moral repugnancy of objective realist accounts that we located earlier. If value is extrinsic, I am only obliged to respect an agent's claims or reasons if I first share them. Without being aware of it, Slattery's empty agent objection is picking out this precise problem. He then observes that in cases of community, this problem does not arise. This is because persons in communities share ends.

However, the underlying problem is not that $A$ and $B$ lack a communal bond. The problem is that the operating conception of value posits that they must. If value lies outside the agent, as Gewirth's view 
assumes, then, as Slattery points out, Gewirth's account needs the additional community premise. But we do not have to, and should not, adopt Gewirth's assumption.

The intersubjectivist picture of value shows us that two agents need not be from the same community to have the obligation to respect each other's ends. With this understanding, we can escape Slattery's objection, because on the intersubjectivist model, there is something in our conception of ourselves that requires or justifies the assertion that $B$ respect $A$ 's ends: $A$ 's is valuable in himself as a valuer, and his ends are the expression of that unique human capacity to value. The intersubjectivist values the agent, not the end, and upon seeing that $A$ has reasons and is making a claim, recognizes that she could share in those ends. For the intersubjectivist, there can never be an "empty agent," because agents are the source of all value.

We can hold, then, that Gewirth's view can be saved from Slattery's objection if we adopt the intersubjectivist stance on value, if only because when we remove the objective realist conception, the grounds on which the objection operate fall away. A similar analysis holds for Slattery's limited inference objection, which as rehearsed above, rests on the same operative grounds.

However, the intersubjectivist cannot solve all of Gewirth's problems. The view is still too abstract and detached from the realities of the development of human rights doctrines to possess our necessary feature of historical veracity.

It is more constructive to turn our attention, at this point, to Slattery's view. I will suggest that his overall picture can be given more strength by buttressing it with the intersubjective understanding of agent-neutral value, as opposed to the objective realist conception.

Recall that the view posits that human rights are concrete, communal, historically grounded, and (paradoxically) immanently transcendent. In my view, an appeal to intersubjectivity better explains how human right come to possess these four features. 
We will turn first to concreteness. Recall Slattery's observation that although human rights are cast in abstract terms, they arise out of concrete moral insights into relations with others, such as Jim's interactions with Martin (451). On the objective realist picture, Jim's moral insight must be based on some kind of epistemic access to the independently good projects that Martin has taken up. Those goods exist independent of Martin and Jim, and once Jim recognizes that Martin is valuing the similar ends, he sees Martin's reasons as holding for him. This explanation seems incorrect for two reasons. First, it offers an utterly abstract account of what seems to be a series of everyday interactions and ordinary affairs. Second, and perhaps more importantly, on this explanation, Jim is valuing Martin's ends, not Martin. That is, the account provided does not describe a concrete moral insight arising out of engagement with another person, but rather an abstract experience of another's objectively good ends or practical reasons. This analysis is troublesome because it participates in the consequentialist error cited above: it sees the business of morality in bringing things about, rather than doing things together.

By contrast, the intersubjectivist account explains why human rights arise out of concrete moral insights in our relations with others. For the intersubjectivist, the idea of recognizing another's claims is predicated on recognizing the other agent. Regarding the other as equally real, or seeing him as the same kind of being with the same capacity to value, is what constructs the agent-neutral human rights values from their individual agent-relative components. Concrete interpersonal relations are what allow for the very possibility of agent-neutral reasons, and thus, human rights.

Second, we turn to the necessarily communal nature of human rights. We can break down this feature into three concerns, each of which can be deal with separately. The first communal aspect of rights can be tracked by our earlier recognition that any account of human rights might posit that rights presuppose communal bonds. On the objective realist conception, we must again posit independent and epistemologically accessible goods that all persons must share. This is still open to the morally 
repugnant requirement of sharing ends before respecting obligations. On the contrary, the intersubjectivist provides a better explanation for why this must be so: as just argued above, concrete interpersonal relations of at least two agents are what allow for the very possibility of agent-neutral reasons.

The second way in which human rights are communal is tracked by our necessary formal feature of reciprocity: they must be able to support the possibility of reciprocal obligations between persons who share those obligations. $B$ must be able to recognize and take $A$ 's claims as reasons for her. Again, the objective realist faces the same morally repugnant requirement of ends-sharing before obligationrespecting. The intersubjectivist sees the potential of sharing as the only way that such agent-neutral reasons could be generated, thus not only explaining, but requiring reciprocity.

The third sense in which human rights might be communal is the deeper, fuller bonds shared between actual close-knit communities, families, and other relationships. On the objective realist account, it is not possible to capture this felt-difference without perhaps appealing to some kind of "better" or more profound agent-independent good that are community, family, or relationship-specific. The intersubjectivist gives a more plausible explanation: not only do the members of these categories of relationships respect each other's humanity first, they also happen to share the same ends, namely, the valuing of the relationship they are a part of.

We can now turn to the Slattery's third feature, that human rights are historically grounded. Any account must be able to recognize and appreciate that these concrete and communal obligations arise out of the particular circumstances in which those relations exist. Again, an objective realist account will not be able to accommodate the contingencies of history, without making some large metaphysical adjustments as time passes, rights movements take root and gain acceptance. For instance, it is difficult, if not impossible, to provide a plausible story about why particular rights were not recognized at certain 
times, or how they came to be recognized if the reasons that compel their respect are mind independent and epistemically accessible. In contrast, a human rights account undergirded by an intersubjectivist account of reasons can simply state that the history of any one rights movement, from non-recognition to recognition, is a process of moving from a state of moral evil in the former to morally estimable behavior in the latter. Until persons are recognized as persons first, and not discarded because they do not share our ends, we are committing moral atrocities. This analysis holds for both the practice of rights recognition writ large, say, within a society or country, and for the practice of rights recognition at the level of individual human interaction.

Finally, we can turn to perhaps the most interesting and puzzling feature of human rights that Slattery identifies. Recall that Slattery observes a kind of paradox inherent in all human rights claims: they gesture at or promise some kind of moral transcendence, they reach for a higher moral truth, while at the same time being already recognized and instantiated in the respect between community members. Slattery calls this property the immanently-transcendent nature of human rights.

The objective realist about value cannot fully explain the paradox. Certainly, he has the advantage of being able to cite a transcendent truth in a limited sense, as he affirms the existence of agent-independent goods. Perhaps then, he can state that what human rights promise us is an epistemological discovery of the most basic of those goods, the ones that hold for all persons. However, his explanatory power runs out here. Although he can explain the transcendent half of this peculiar property, he cannot, for the reasons above, make sense of their communal instantiation. Furthermore, he still faces the problem of moral repugnance when ends are not shared. Without an explanation for the second half of this paradox, this property of human rights remains opaque.

The intersubjectivist can do better. She, unlike the objective realist, can easily explain the immanence of human rights claims, citing either the fact that for agent-neutral value to be possible at all, 
agents must admit that other's ends could be shared, or, in instances of deeper immanence, that the ends are actually shared in special relationships.

But she can also explain transcendence. She alone can provide us with an account of the source of all value, the location of the good, the font of moral truth. She just points to herself, and to any other agent: the creators, sharers, and keepers of all that can possibly be good. Unlike the consequentialist or the objective realist, who locate the good independent of agents, the intersubjectivist starts with the basic premise that we, agents, are the source of normative claims. Although we will never know for certain, this, I think, is a plausible candidate for the higher moral truth that human rights hint at.

Ending Where We began: From Rights to Reasons, and Back Again.

This discussion has led us back to where we began in more senses than one. Remember, that we started with rights: normative claims that persons can make on others in virtue of certain features of themselves, with those features justifying why that obligation is owed. Gewirth called these kinds of rights claim-rights, and they had a particular logical structure. We then moved to reasons, and discussed the preconditions under which those claim-rights could even be possible. By reviving Nagel's position in the Possibility of Altrusism, we acknowledged that there are reasons that hold for more than just one or some agents, and further, that it must be reasons like these that ground for human rights. After exploring the distinction between objective realism and intersubjectivism, we eschewed the former and embraced the latter. This led us to realize that the only possible reasons that could ground human rights were the intersubjective reasons we could share - the ones that we recognized could hold for all of us, because they came from other valuers, like us. That is, we recognized that we ourselves are the source of normative claims. 
And with that, we have come full circle. The reasons we have discovered, intersubjectively agent-neutral in kind, are themselves normative claims, exerting moral force over all of us because of our shared capacity to create and recognize value. This shared capacity provides us with Gewirth's justifying ground, or $Y$, on which rights can be claimed and respected. This feature, of being a reasoner, and therefore, a valuer, both creates and justifies the presence of our obligations to one another. Claimrights and intersubjective reasons share the same structure: $A$, agent and value-creator, has an enforceable claim that $B$, a fellow value-creator, recognize and respect his ability to create value and help him realize his ends. The justifying ground, $Y$, is that $A$, like $B$, is good in himself because of his status as value-creator. We can now clearly see Gewirth's mistake. It is an error to locate the good in our ends. The good is not in the end itself, only realized when some state of affairs is brought about. The good lies before that, when we ourselves create it. And, as value creators, we are ends in ourselves. That recognition, more so than any other, is what must undergird human rights. 


\section{Works Cited}

Plato: Complete Works. John M Cooper, ed. New York: Hackett Publishing Company, 1997.

Gewirth, Alan. Reason and Morality. Chicago: University of Chicago Press, 1978.

--- $\quad$ Human Rights. Chicago: University of Chicago Press, 1982.

Nagel, Thomas. The Possibility of Altruism. New Jersey: Princeton University Press, 1970.

--- $\quad$ The View From Nowhere. New York: Oxford University Press, 1986.

Korsgaard, Christine M. “The Reasons We Can Share.” Altruism. Ellen Frankel Paul, Fred D. Miller, and Jeffrey Paul, eds. New York: Cambridge University Press, 1993. 24-51. 